\title{
The Discordance between Network Excitability and Cognitive Performance Following Vigabatrin Treatment during Epileptogenesis
}

\author{
Ming-Chi Lai ${ }^{1}$ and Chin-Wei Huang ${ }^{2, *(D)}$ \\ 1 Department of Pediatrics, Chi-Mei Medical Center, Tainan 71004, Taiwan; 860811@mail.chimei.org.tw \\ 2 Department of Neurology, National Cheng Kung University Hospital, College of Medicine, \\ National Cheng Kung University, Tainan 70101, Taiwan \\ * Correspondence: huangcw@mail.ncku.edu.tw; Tel.: +886-6-2353535-5485
}

Citation: Lai, M.-C.; Huang, C.-W. The Discordance between Network Excitability and Cognitive

Performance Following Vigabatrin Treatment during Epileptogenesis. Life 2021, 11, 1213. https:/ / doi.org/ $10.3390 /$ life11111213

Academic Editors: Chiara Villa and Byung-Chang Suh

Received: 5 October 2021

Accepted: 8 November 2021

Published: 10 November 2021

Publisher's Note: MDPI stays neutral with regard to jurisdictional claims in published maps and institutional affiliations.

Copyright: (c) 2021 by the authors. Licensee MDPI, Basel, Switzerland. This article is an open access article distributed under the terms and conditions of the Creative Commons Attribution (CC BY) license (https:/ / creativecommons.org/licenses/by/ $4.0 /)$.

\begin{abstract}
Vigabatrin (VGB), a potent selective $\gamma$-aminobutyric acid transaminase (GABA-T) inhibitor, is an approved non-traditional anti-seizure drug for patients with intractable epilepsy. Nevertheless, its effect on epileptogenesis, and whether this effect is correlated with post-epileptogenic cognitive function remain unclear. Based on lithium-pilocarpine-induced seizure modeling, we evaluated the effect of VGB on epileptogenesis and neuronal damage following status epilepticus in SpragueDawley rats. Cognitive evaluations were performed with the aid of inhibitory avoidance testing. We found that VGB could interrupt epileptogenesis by reducing spontaneous recurrent seizures, hippocampal neuronal damage, and chronic mossy fiber sprouting. Nevertheless, VGB did not help with the retention of cognitive performance. Our findings suggest that further research into the role of VGB in epileptogenesis and the treatment of epilepsy in clinical practice is warranted.
\end{abstract}

Keywords: vigabatrin; pilocarpine; epileptogenesis; cognition

\section{Introduction}

Vigabatrin (VGB) is a potent selective $\gamma$-aminobutyric acid transaminase (GABA-T) inhibitor with anti-seizure activity which has been approved as a monotherapy for infantile spasms and as an adjunctive therapy for refractory complex partial seizures [1-3]. Earlier studies have demonstrated that it increases the levels of the inhibitory neurotransmitter GABA in a dose-dependent manner in the brains of mice and rats and in the cerebrospinal fluid of patients with epilepsy [4-7]. In addition to its GABAergic effect, we have recently found that VGB modulates neuronal calcium-activated potassium channels, suggesting that it is equipped with various mechanisms of action [8]. In animal models, it has been demonstrated that VGB can abort acute focally evoked pilocarpine-induced seizures [9], pentylenetetrazole (PTZ)-induced seizures [10], and tetrodotoxin-induced infantile spasms [11]. Furthermore, although it has exhibited variable anticonvulsant potential, it generally shows broad-spectrum anticonvulsant activity $[4,12]$.

Despite its beneficial impacts, it is currently unclear whether VGB administered after pilocarpine-induced status epilepticus can interrupt epileptogenesis. It has been found to be detrimental to the recovery process when administered following a focal cortical insult, in contrast to the effects of phenobarbital and diazepam [13]. Another study has reported that VGB results in incomplete protection of the hippocampus, which is widely believed to be involved in temporal lobe seizure activity, and there is evidence that VGB has no influence on the generation of epilepsy [14], suggesting that the expression of the protein glutamic acid decarboxylase is independent of seizures. Finally, a recent study on a TSC/mTOR-dependent epilepsy mouse model has shown that VGB does not prevent epilepsy but significantly delays the onset of seizures and lowers their frequency [15].

Some research suggests the existence of a link between seizure activity and cognitive impairment. One such study, using a kainic acid model of chronic temporal lobe epilepsy 
(TLE), has highlighted neuropathological features of TLE, including reduced neurogenesis and aberrant migration of newly born neurons and aberrant mossy fiber sprouting in the hippocampus, which appear to be correlated with cognitive impairment [16]. Hippocampal damage is closely related to memory impairment, so the protection of the hippocampus might help to maintain memory processes [14]. Such findings raise the question of whether VGB might impact cognitive function in addition to its role in seizure activity. In fact, it has been noted that increased cognitive risk is associated with persistent or poorly controlled seizures [16]. Nonetheless, the cognitive effects of VGB have been incompletely evaluated and remain inconclusive $[17,18]$. Furthermore, the clinical effects of VGB, which are relevant to mitigating the risk of both cognitive impairment and seizure activity, have proven to be either unclear or favorable depending on the etiology and preexisting developmental profile of seizure activity $[19,20]$.

The current evidence suggests that more research is required to ascertain the effectiveness of VGB. For example, the relationships between cognitive performance, seizure severity, and the effects of VGB on animals with chronic pilocarpine-induced epilepsy remain to be determined. The possibility that spontaneous recurrent seizures and network excitability following pilocarpine-induced epileptogenesis have an impact on cognitive function must also be verified. As a result, in this study, we attempt to determine if the administration of VGB following pilocarpine-induced status epilepticus can help prevent epileptogenesis and preserve cognitive performance.

\section{Materials and Methods}

All experiments were conducted in accordance with the specifications proposed by the Experimental Ethics Committee of National Cheng Kung University (NCKU). The procedures for animal experimentation were reviewed and approved by the Institutional Animal Care and Use Committee, NCKU (Approval No.: 109218).

\subsection{Animals}

Adult male Sprague-Dawley rats weighing 180-200 gm were purchased from NCKU. They were housed in the university's Animal Center and allowed free access to water and a pelleted rodent diet (Richmond Standard; PMI Feeds, St. Louis, MO, USA). A cycle of alternating 12-h periods of light and dark was used to ensure the animals' circadian rhythms functioned under normal, environmentally relevant conditions [21]. Efforts were made to keep the number of rats used to a minimum.

\subsection{In Vivo Experiments}

Grouping

Lithium-Pilocarpine Seizure Modeling

On day 1 , the rats were injected with lithium chloride ( $3 \mathrm{meq} / \mathrm{kg} ;$ i.p.), and methylscopolamine ( $25 \mathrm{mg} / \mathrm{kg}$; s.c.) prior to their experiencing pilocarpine-induced seizures $(60 \mathrm{mg} / \mathrm{kg}$; s.c.). The behavioral characteristics of the rats during the epileptic seizures were similar to those reported earlier in our laboratory and elsewhere [22-24], and the behavioral stages of the seizures were evaluated based on the Racine scale [25]. Over the following 15 to $20 \mathrm{~min}$, they exhibited mouth and facial movements, head bobbing and nodding, scratching, masticatory automatisms, and exploratory behavior (stages 1-2). Episodes of myoclonic movements of the head and bilateral forelimbs (stage 3) started at 20 to $25 \mathrm{~min}$ and progressed to status epilepticus (stages 4-5), with rearing and falling at about $50 \mathrm{~min}$ after the pilocarpine injection. To measure seizure latency, the time intervals from the administration of pilocarpine to the onset of overt seizure behaviors (stage 3) were calculated. Diazepam (5 mg/kg, i.p.) was administered to diminish the intensity of the seizures if status epilepticus lasted for $90 \mathrm{~min}$. Status epilepticus-related mortality was recorded during the first $24 \mathrm{~h}$ after the initial onset. All the rats were monitored for the first $24 \mathrm{~h}$ after status epilepticus, and supportive care was implemented, including maintaining body temperature, feeding, and providing adequate hydration. 
The rats were then divided into an experimental group (VGB) (orally fed $30 \mathrm{mg} / \mathrm{kg}$ of VGB twice daily for 7 consecutive days, days 2-9) and a control normal saline (NS) group (orally fed normal saline daily for 7 consecutive days). Each group contained 7 animals in each set of experiments. After this latent phase of epileptogenesis (days 2-9), the rats gradually developed chronic epilepsy characterized by spontaneous recurrent seizures (SRS). We started monitoring the seizure frequency in the rats on days 10-15 after status epilepticus. Each rat was monitored with a video camera set above the cage $8 \mathrm{~h}$ per day for 5 consecutive days $[24,26]$. All monitoring of the SRS was conducted by a trained technician blinded to the experimental design. The videos were watched to identify any evidence of seizure behavior (running, jumping, rearing, lordosis, an erect tail, and so on). If any seizure-like activity was seen, the video was stopped and viewed again to evaluate the behavior for possible seizures. The experimental protocol is shown in Figure 1.

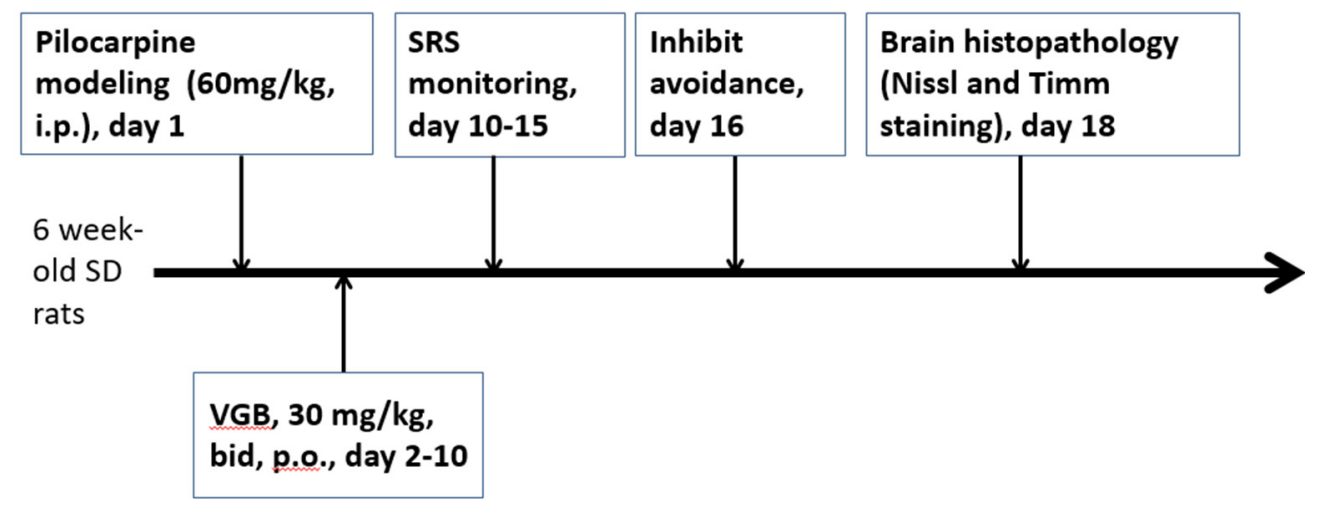

Figure 1. The experimental protocol. SD: Sprague-Dawley; VGB: vigabatrin; SRS: spontaneous recurrent seizure.

\subsection{Inhibitory Avoidance Task}

A single-trial inhibitory avoidance (IA) task, which is a hippocampus-dependent learning task, was used to evaluate the different stages of memory in rats on day 16 , after the monitoring of SRS. The apparatus consisted of one illuminated compartment and one dark compartment. A shock generator was connected to the floor of the dark compartment. Before the experiment, the rat was kept in a dimly lit room for $1 \mathrm{~h}$ to adjust to the brightness level and environment. During the training phase, the rat was placed in the illuminated compartment facing away from the door. As the rat turned around, the door was opened. When the rat entered the dark compartment, the door was closed, and the rat was given a $1.0 \mathrm{~mA} / 1$-s shock. The reaction to the shock was identified as flinch, vocalization, or locomotion. The rat was then removed from the alley and returned to its home cage. A retention test was conducted 1, 3, and $24 \mathrm{~h}$ after the training phase to evaluate short-term, intermediate, and long-term memory, respectively. This test involved again placing the rat in the illuminated compartment, after which its hesitancy to step into the dark compartment was recorded as a measure of retention. Rats that did not enter the dark compartment within $600 \mathrm{~s}$ were removed from the alley.

\subsection{Histopathology}

\subsubsection{Cresyl Violet Staining}

On day 18 , the rats were anesthetized with an overdose of pentothal $(60 \mathrm{mg} / \mathrm{kg}$; i.p.), and then their brains were removed and stored at $-80^{\circ} \mathrm{C}$. The next step involved fixing coronal sections (20- $\mu \mathrm{m}$ thick) of the hippocampus in formaldehyde in order to be stained with cresyl violet, as has been described in previous research [24,27]. The hippocampal subfields were defined by means of an imaginary line connecting the blade tips of the granule cell layer, which made it possible to isolate the cornu ammonis (CA) and separate its regions: CA3c (medially) from CA3b (laterally), and CA2 from CA1 [23,24]. The cresyl violet-stained sections then underwent a gross examination for indications of damage in the 
hippocampus. In order to assess neuron damage, the cells were counted using Nissl-stained sections $(10-\mu \mathrm{m}$ thick), and the images were magnified $(\times 400)$ using a computerized image analysis system (Image Plus 2.0; Motic, Richmond, British Columbia, Canada) in order to facilitate the counting. The severity of neuron damage in different subfields of the hippocampus was scored semi-quantitatively as follows: $0=$ no damage, $1=$ less than $10 \%, 2$ = between $11 \%$ and $50 \%$ neuron loss, and $3=$ equal to or greater than $50 \%$ neuron loss $[28,29]$. Scores for the VGB and NS groups were obtained by an investigator blinded to the study design, and then an average score was calculated for each group.

\subsubsection{Timm's Staining}

On day 18 , after the rats' brains had been removed, coronal sections (20- $\mu \mathrm{m}$ thick) were cut through the entire hippocampus on a freezing microtome. Timm staining was performed on every sixth section [30] from the septal region to the temporal region of the hippocampus (the region between 2.8 and $3.8 \mathrm{~mm}$ posterior to the bregma). The sections were processed in the dark for $10-45 \mathrm{~min}$ in $200 \mathrm{~mL}$ of a solution containing $5.1 \mathrm{~g}$ of citric acid, $4.7 \mathrm{~g}$ of sodium citrate, $3.47 \mathrm{~g}$ of hydroquinone, $212.25 \mathrm{mg}$ of $\mathrm{AgNO}_{3}$, and $120 \mathrm{~mL}$ of $50 \%$ arabic gum. We used a semi-quantitative scale to evaluate the degree of mossy fiber sprouting in the pyramidal cell layer of the CA3 hippocampal region, in the granular cell layer and inner molecular layer of the dentate gyrus, and in the infra-pyramidal mossy fiber area between CA3 and the dentate gyrus [23,24,27]. The scale scores included: $0=$ no granules, 1 = occasional discrete granule bundles, 2 = occasional-to-moderate granules, 3 = prominent granules, $4=$ prominent near-continuous granule bands, and $5=$ continuous or nearly continuous dense granule bands.

\subsection{Drugs and Solutions}

VGB, scopolamine, and pilocarpine were purchased from Sigma-Aldrich (St. Louis, MO, USA). All other chemicals, unless otherwise noted, were locally purchased and of reagent grade.

\subsection{Statistical Analysis}

In this paper, the results of the analyses of the continuous data are expressed as means \pm standard error of the mean (SEM), unless otherwise indicated. With the statistical significance set at $p<0.05$, the continuous variables were assessed using either $t$-tests or a one-way analysis of variance (ANOVA) (SPSS 17.0; SPSS Institute, Chicago, IL, USA), followed by Fisher's least significant difference (LSD) test. The Shapiro-Wilk test of the normality of the distribution of the dataset was performed, and when data were not normally distributed, analyses were done using the ANOVA (the Kruskal-Wallis H test), followed by Dunn's multiple comparison test. Analyses were also done using $\chi^{2}$ tests, the Yates $\chi^{2}$ test, and Fisher's exact probability test with the nominal variables.

\section{Results}

\subsection{VGB-Treated Rats Had Fewer Spontaneous Recurrent Seizures}

After a latent phase of one week following status epilepticus, the rats developed spontaneous seizures. These SRS were characterized by spontaneous convulsions [31] with head nodding, forelimb clonus, rearing, and falling. The mean number of daily spontaneous seizures exhibited per rat was calculated based on regular daily 4-h visual monitoring from 14 to 28 days after pilocarpine-induced status epilepticus. The rats were evaluated in their respective group, with the VGB-treated group having fewer rats with SRS, compared to the normal saline group (VGB: $5 / 12$, or $41.67 \%$; NS: $10 / 12$, or $83.33 \%$, $p=0.03$ ) (see Figure 2A). The rats in the VGB group had fewer severe seizures (stage 3 and above), compared to the NS group (VGB: $2 / 5$, or $40 \%$; NS: $9 / 10$, or $90 \%, p=0.03$ ) (see Figure $2 B$ ). The mean number of daily seizures in the VGB group was significantly smaller than in the NS group (VGB: $4.6 \pm 1.14$; NS: $6.8 \pm 2.62, p=0.04$ ) (See Figure 2C). In sum, 
fewer rats in the VGB-treated group exhibited SRS, and this group showed fewer severe seizures and daily seizures.

A

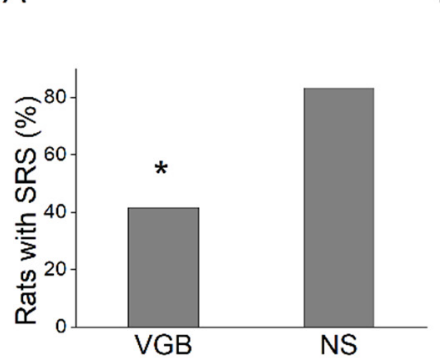

B

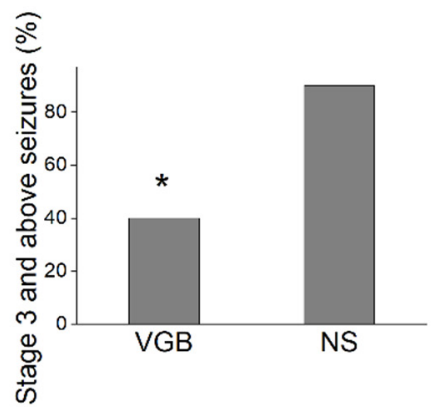

C

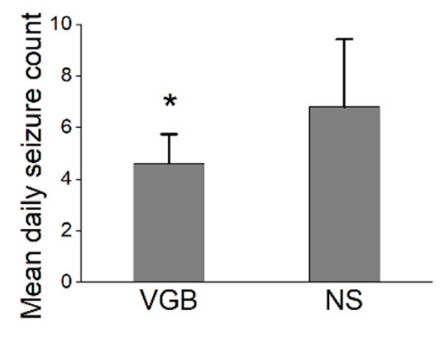

Figure 2. VGB-treated rats had fewer spontaneous recurrent seizures. (A) The VGB-treated group had fewer rats with SRS, compared to the normal saline group (VGB: $41.67 \%$; NS: $183.33 \%{ }^{*} p<0.05$ ). (B) The VGB group had fewer severe seizures (stage 3 and above), as compared to the NS group (VGB: 40\%; NS: 90\%, ${ }^{*} p<0.05$ ). (C) The mean count of daily seizures for the VGB group was significantly lower than that for the NS group (VGB: $\left.4.6 \pm 1.14 ; \mathrm{NS}: 6.8 \pm 2.62,{ }^{*} p<0.05\right)(N=7$ in each group).

\subsection{The VGB-Treated Rats Had Less Post-Status Epilepticus Chronic Hippocampal Damage}

After epileptogenesis, the cresyl violet staining showed that the VGB group had significantly less neuron loss in the hippocampal CA3 field (see Figure 3A) than the NS group (see Figure 3B). A blind semi-quantitative analysis showed that the VGB group had significantly less hippocampal neuronal damage compared with the NS group (VGB: $2.1 \pm 0.3$; NS: $2.9 \pm 0.4, p<0.01$ ) (See Figure 3C). In conclusion, the VGB-treated group exhibited less chronic hippocampal damage post-pilocarpine-induced status epilepticus.

A

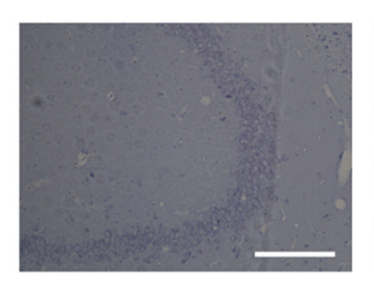

B

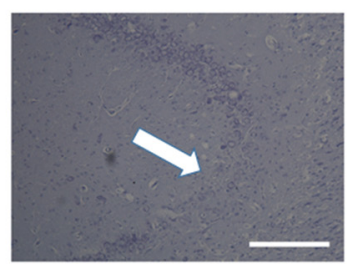

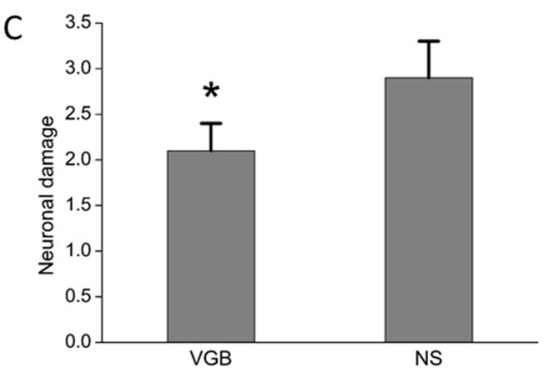

Figure 3. VGB-treated rats had less post-status epilepticus chronic hippocampal damage. The VGB group (A) had significantly less neuron loss in the hippocampal CA3 region than was the case in the NS group (B) (the arrow shows the cresyl violet staining). A blind semi-quantitative analysis (C) showed that the VGB group had significantly less hippocampal neuronal damage compared with the NS group $\left({ }^{*} p<0.01\right)(N=7$ in each group). The scale bar $=200 \mu \mathrm{M}$.

\subsection{VGB-Treated Rats Had Less Aberrant Mossy Fiber Sprouting}

Eighteen days following status epilepticus, Timm staining (see Panels A and B in Figure 4) showed significantly fewer dense mossy fibers sprouting in the hippocampal CA3 region of the VGB rats than in the NS rats (Timm scores of VGB: $1.3 \pm 0.2$, and NS: $3.8 \pm 0.4, p<0.05$ ) (see Panel C in Figure 4). Therefore, the VGB-treated rats showed less sprouting of dense mossy fibers in the hippocampus. 
A

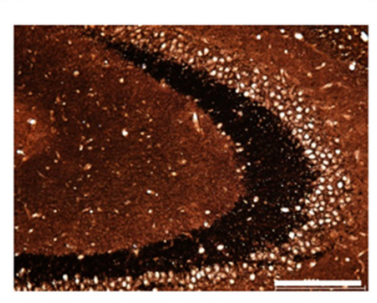

B

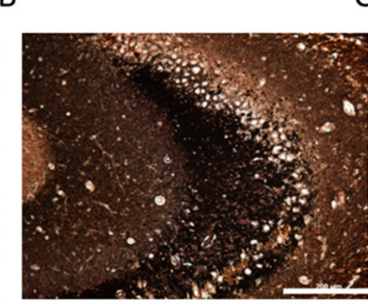

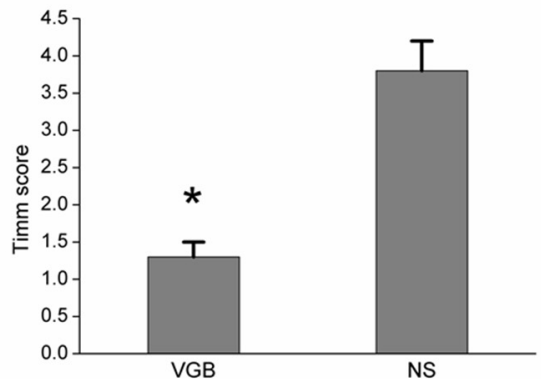

Figure 4. VGB-treated rats had less mossy fiber sprouting. Timm's staining (A,B) showed significantly fewer mossy fibers sprouting in the hippocampal CA3 region of the VGB group (A) than in the NS group (B). The Timm's score (C) for VGB vs. NS were significant, $\left.{ }^{*} p<0.05\right)(N=7$ in each group). The scale bar $=200 \mu \mathrm{M}$.

\subsection{VGB-Treated Rats Did Not Preserve Inhibitory Avoidance Test Performance}

The duration of the initial hesitancy to enter the dark compartment during training did not significantly differ between the two groups. After training, the time elapsed before the rats entered the dark compartment also did not differ significantly between the VGB and NS groups, although the former tended to exhibit relatively more retention time of the avoidance response after training (VGB: $157.5 \pm 90 \mathrm{~s}$; NS: $128.9 \pm 80 \mathrm{~s}, p=0.18$ ) during the chronic stage after pilocarpine-induced status epilepticus (See Figure 5). In conclusion, the cognitive performance of the rats in the VGB-treated group was not preserved during the inhibitory avoidance test.

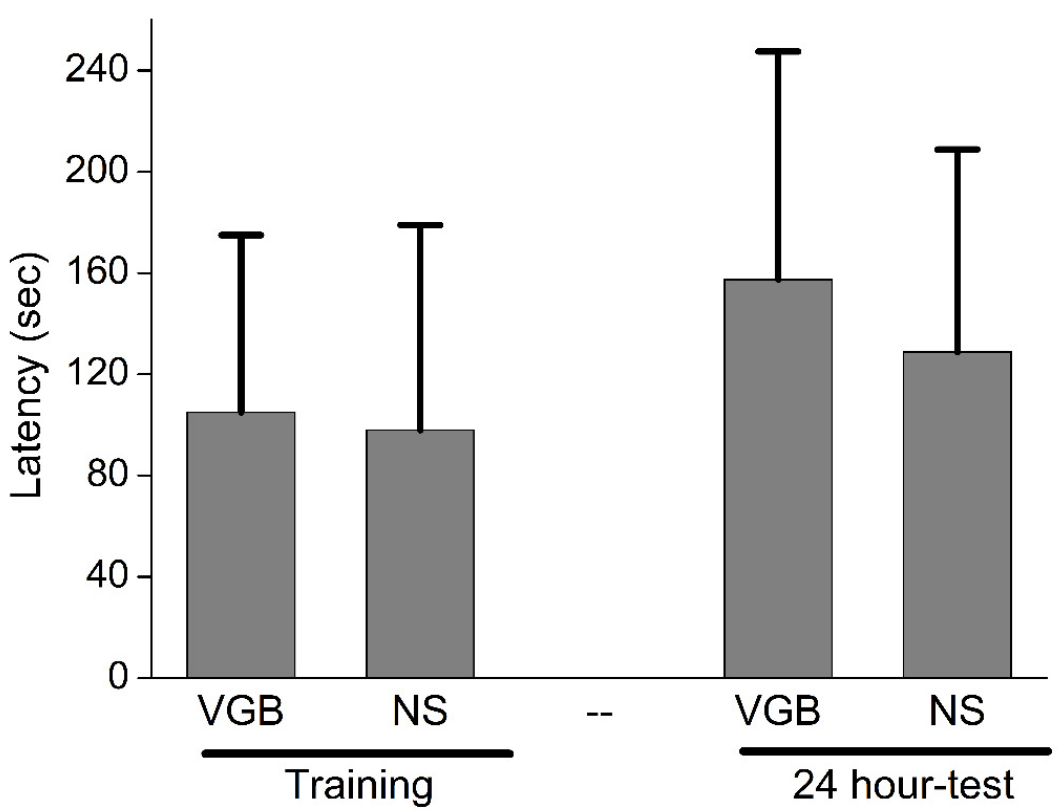

Figure 5. VGB-treated rats did not preserve inhibitory avoidance test performance. The duration of the hesitancy to enter the dark compartment during training and after training did not differ significantly between the VGB and NS groups (VGB vs. control, $p=0.18$ ).

\section{Discussion}

In this study, we demonstrated that VGB was effective in ameliorating lithiumpilocarpine-induced epileptogenesis, and in reducing hippocampal neuronal damage and mossy fiber sprouting. Nevertheless, VGB did not allow for retention of cognitive performance following epileptogenesis in our inhibitory avoidance model.

It has been reported that VGB administered to patients with epilepsy showed few adverse effects on cognition [32,33] and fewer adverse effects than carbamazepine on cognitive processes, including memory, psychomotor speed, and flexibility in mental 
processing [34]. It is generally regarded as harmless to the cognitive performance when used as an antiepileptic drug to treat patients with newly diagnosed and intractable epilepsy. In our study, however, it did not help to retain cognitive functions during the epileptogenesis stage, although it did attenuate spontaneous recurrent seizures and reduce acute neuronal damage and aberrant excitatory networks. This suggests that the frequency of recurrent seizures, a common indicator of cognitive function, is probably not actively involved in determining the cognitive activity associated with using VGB to treat seizures.

Another possible explanation is that significant neuronal damage occurs immediately after status epilepticus, leading to severe cognitive deficits. Although subsequent treatment with VGB attenuated neuronal hyperexcitability, leading to less frequent seizures and secondary neuronal damage, the altered functioning could not be restored, at least during the epileptogenesis stage.

GABAergic interneurons play a critical role in higher brain functions, and signaling from interneurons to astrocytes normally sustains important cortical information processing and complex behaviors [35]. In an epileptic network with extensive aberrant neuronal sprouting and altered ionic mechanisms, the effect of VGB on GABAergic activity probably makes it impossible for GABAergic interneurons to exert normal signaling and behavioral responses. Furthermore, the stage of epileptogenesis is different from the stage of chronic static epilepsy, and it is probable that the wide spectrum of cognitive deficits observed in chronic epilepsy cannot be attributed to seizures and antiepileptic drugs alone. Etiology and aberrant synaptic transmissions may also play important roles in cognitive impairment $[18,36]$.

One study found no anti-epileptogenic effects of VGB in an animal model examining kainic acid-induced seizures [37], although the correlation between the severity of neuronal damage and the extent of mossy fiber sprouting was similar to that found in our study. Probable reasons for their findings are the severe hippocampal damage and inter-animal variability seen in their model. Earlier findings have shown that VGB delayed the development of kindling [38], which is in line with our findings. Another study has shown VGB to have protective effects in the CA3 pyramidal cell layer in a pilocarpine model [14] although the latency to seizure was not altered.

The possibility has been raised that mossy fiber sprouting disrupts the functioning of hippocampal neuronal circuits and contributes to cognitive impairment in models of temporal lobe epilepsy [39]. Earlier studies evaluating hippocampal neurogenesis have not found consistent evidence of its impact on cognitive performance, and those examining mossy fiber sprouting in temporal lobe epilepsy suggest that the link between mossy fiber sprouting and cognitive function remains inconclusive. Interestingly, the use of valproic acid to block seizure-induced neurogenesis has been shown to have a protective effect against cognitive impairment [40]. Our finding that VGB did not help retain cognitive performance although it attenuated mossy fiber sprouting and epileptogenesis in our pilocarpine model is supported by a recent study in which an overall reduction in the number of abnormal neuronal integrations, including mossy fiber sprouting, in epileptic rats did not produce any difference in their performance on the Morris water maze test compared with that of rats whose neurogenesis had not been ablated [41].

It has been reported that, following pilocarpine-induced status epilepticus, only epilepsy-prone rats showed accelerated forgetting rates and reduced learning rates during the Morris water maze task, compared to both rats that did not develop epilepsy and rats used as controls, suggesting that cognitive deficits functioned as a biomarker of epileptogenesis in this rat model of epilepsy [42]. However, our study using an inhibitory avoidance task does not support this finding. Both our VGB group and our control group showed similar cognitive profiles, with differences in epileptogenicity. Whether this result is related to the severity of the neuron loss in both groups, as we mentioned earlier, or to the ratio of normal versus abnormal/epileptic neurons remains to be determined. A recent study has shown that VGB, with the aid of inhibitory avoidance and open-field tasks, did not affect short-term memory or long-term memory, but it impaired exploration 
and locomotion performance [43], probably as a result of its sedative effect. Whether this effect contributed to the lack of difference in inhibitory avoidance behavior in our study remains to be determined in future studies.

According to the literature, some patients on VGB therapy develop visual field defects. It has been suggested that around one third of them experience such loss of vision [44]. Nonetheless, visual acuity and color vision seem to remain stable in all these patients regardless of changes in their field of vision [45], and it has been suggested that VGBassociated visual field defects are an idiosyncratic drug reaction within the neurosensory retina $[44,45]$. In the context of our study, if visual field defects had affected cognitive performance, we would have seen differences between the VGB-treated group and the NS group during the training phase of our inhibitory avoidance test. However, their performance at this point was similar, and their memory retention measured later did not show any significant differences between the groups. Therefore, we believe that the possible presence of visual field deficits in the rats would not have affected their cognitive performance during this task.

There are multiple factors affecting cognitive performance in patients with epilepsy [46], and there is contradictory evidence of a relationship between seizure control and/or structural damage, on the one hand, and cognitive performance, on the other [47]. Although clinical epileptic seizures tend to resolve on their own or markedly improve, cognitive outcomes are not always favorable, and a structural etiology typically confers a poor prognosis [48]. In addition, some changes in the brain regions that are important for behavior and cognition, as well as altered thalamofrontal neurodevelopment occurring during brain maturation have been shown to be independent of seizure variables [48,49]. Finally, our study findings support the notion that the severity of neuronal damage and the reduced frequency of recurrent seizures do not necessarily correlate with better cognitive performance during the epileptogenesis stage.

\section{Conclusions}

Our study with rats showed VGB to be effective in interrupting epileptogenesis and in reducing hippocampal neuronal damage and mossy fiber sprouting, but not in retaining cognitive performance. It should also be noted that, although our data are not sufficient to guarantee similar results if VGB is administered to humans with different types of epilepsy, clinical attention to the use of VGB therapy for patients with epilepsy is recommended.

Author Contributions: Conceptualization by M.-C.L. and C.-W.H.; methodology by C.-W.H.; validation by M.-C.L. and C.-W.H.; investigation by M.-C.L. and C.-W.H.; data curation by M.-C.L. and C.-W.H.; writing-original draft preparation by M.-C.L. and C.-W.H.; writing-review and editing by M.-C.L. and C.-W.H.; funding acquisition by C.-W.H. All authors have read and agreed to the published version of the manuscript.

Funding: This work was supported in part by grants from the Ministry of Science and Technology, Taiwan (107-2314-B-006-018-, 107-2320-B-006-019-, 108-2320-B-006-023-, and 109-2314-B-006-034-MY3).

Institutional Review Board Statement: The procedures for animal experimentation were reviewed and approved by the Institutional Animal Care and Use Committee (Approval No.: 109218).

Informed Consent Statement: Not applicable.

Data Availability Statement: The data are available upon request made to the correspondence author.

Acknowledgments: The authors would like to thank Jen-Nan Wu for her technical assistance during this research.

Conflicts of Interest: The authors declare that there is no conflict of interest. 


\section{References}

1. Lux, A.L.; Edwards, S.W.; Hancock, E.; Johnson, A.L.; Kennedy, C.R.; Newton, R.W.; O'Callaghan, F.J.K.; Verity, C.M.; Osborne, J.P. The United Kingdom infantile spasms study comparing vigabatrin with prednisolone or tetracosactide at 14 days: A multicentre, randomised controlled trial. Lancet 2004, 364, 1773-1778. [CrossRef]

2. Hancock, E.C.; Osborne, J.P.; Edwards, S.W. Treatment of infantile spasms. Cochrane Database Syst. Rev. 2008, 6, CD001770.

3. Hemming, K.; Maguire, M.J.; Hutton, J.L.; Marson, A.G. Vigabatrin for refractory partial epilepsy. Cochrane Database Syst. Rev. 2008, 3, CD007302.

4. Schechter, P.J. Vigabatrin. In Current Problems in Epilepsy 4, New Anticonvulsant Drugs; Meldrum, B.S., Porter, P.J., Eds.; John Libby: London, UK, 1986; pp. 265-275.

5. Schechter, P.J.; Hanke, N.F.; Grove, J.; Huebert, N.; Sjoerdsma, A. Biochemical and clinical effects of gamma-vinyl GABA in patients with epilepsy. Neurology 1984, 34, 182-186. [CrossRef]

6. Jung, M.J.; Lippert, B.; Metcalf, B.W.; Böhlen, P.; Schechter, P.J. Gamma-Vinyl GABA (4-amino-hex-5-enoic acid), a new selective irreversible inhibitor of GABA-T: Effects on brain GABA metabolism in mice. J. Neurochem. 1977, 29, 797-802. [CrossRef]

7. Perry, T.L.; Kish, S.J.; Hansen, S. Gamma-Vinyl GABA: Effects of chronic administration on the metabolism of GABA and other amino compounds in rat brain. J. Neurochem. 1979, 32, 1641-1645. [CrossRef] [PubMed]

8. Hung, T.Y.; Huang, H.Y.I.; Wu, S.N.; Huang, C.W. Depressive effectiveness of vigabatrin ( $\gamma$-vinyl-GABA), an antiepileptic drug, in intermediate-conductance calcium-activated potassium channels in human glioma cells. BMC Pharmacol. Toxicol. 2021, 22, 6. [CrossRef]

9. Smolders, I.; Khan, G.M.; Lindekens, H.; Prikken, S.; Marvin, C.A.; Manil, J.; Ebinger, G.; Michotte, Y. Effectiveness of vigabatrin against focally evoked pilocarpine-induced seizures and concomitant changes in extracellular hippocampal and cerebellar glutamate, gamma-aminobutyric acid and dopamine levels, a microdialysis-electrocorticography study in freely moving rats. J. Pharmacol. Exp. Ther. 1997, 283, 1239-1248.

10. Świąder, M.J.; Świąder, K.; Zakrocka, I.; Krzyżanowski, M.; Wróbel, A.; Łuszczki, J.J.; Czuczwar, S.J. Long-term vigabatrin treatment modifies pentylenetetrazole-induced seizures in mice: Focused on GABA brain concentration. Pharmacol. Rep. 2020, 72, 322-330. [CrossRef]

11. Frost, J.D., Jr.; Le, J.T.; Lee, C.L.; Ballester-Rosado, C.; Hrachovy, R.A.; Swann, J.W. Vigabatrin therapy implicates neocortical high frequency oscillations in an animal model of infantile spasms. Neurobiol. Dis. 2015, 82, 1-11. [CrossRef]

12. Richens, A. Potential antiepileptic drugs: Vigabatrin. In Antiepileptic Drugs, 3rd ed.; Levy, R.H., Dreifuss, F.E., Mattson, R.H., Meldrum, B.S., Penry, J.K., Eds.; Raven: New York, NY, USA, 1989; pp. 937-946.

13. Montañez, S.; Kline, A.E.; Selwyn, A.P.; Suozzi, J.C.; Butler, S.E.; Hernandez, T.D. Vigabatrin directed against kindled seizures following cortical insult: Impact on epileptogenesis and somatosensory recovery. J. Neurotrauma 2001, 18, 1255-1266. [CrossRef] [PubMed]

14. André, V.; Dubé, C.; François, J.; Leroy, C.; Rigoulot, M.-A.; Roch, C.; Namer, I.J.; Nehlig, A. Pathogenesis and pharmacology of epilepsy in the lithium-pilocarpine model. Epilepsia 2007, 5, 41-47. [CrossRef]

15. Koene, L.M.C.; van Grondelle, S.E.; Proietti Onori, M.; Wallaard, I.; Kooijman, N.H.R.M.; van Oort, A.; Schreiber, J.; Elgersma, Y. Effects of antiepileptic drugs in a new TSC/mTOR-dependent epilepsy mouse model. Ann. Clin. Transl. Neurol. 2019,6, 1273-1291. [CrossRef] [PubMed]

16. Upadhya, D.; Kodali, M.; Gitai, D.; Castro, O.W.; Zanirati, G.; Upadhya, R.; Attaluri, S.; Mitra, E.; Shuai, B.; Hattiangady, B.; et al. A model of chronic temporal lobe epilepsy presenting constantly rhythmic and robust spontaneous seizures, co-morbidities and hippocampal neuropathology. Aging Dis. 2019, 10, 915-936. [CrossRef] [PubMed]

17. Aldenkamp, A.; Besag, F.; Gobbi, G.; Caplan, R.; Dunn, D.W.; Sillanpää, M. Psychiatric and behavioural disorders in children with epilepsy (ILAE Task Force Report): Adverse cognitive and behavioural effects of antiepileptic drugs in children. Epileptic Disord. 2016, 18, S55-S67.

18. Aldenkamp, A.P.; Bodde, N. Behaviour, cognition and epilepsy. Acta Neurol. Scand. Suppl. 2005, 182, 19-25. [CrossRef] [PubMed]

19. Djuric, M.; Kravljanac, R.; Tadic, B.; Mrlješ-Popovic, N.; Appleton, R.E. Long-term outcome in children with infantile spasms treated with vigabatrin: A cohort of 180 patients. Epilepsia 2014, 55, 1918-1925. [CrossRef]

20. Ljff, D.M.; Aldenkamp, A.P. Cognitive side-effects of antiepileptic drugs in children. In Handbook of Clinical Neurology; Elsevier: Amsterdam, The Netherlands, 2013; Volume 111, pp. 707-718.

21. Hughes, S.; Jagannath, A.; Hankins, M.W.; Foster, R.G.; Peirson, S.N. Photic regulation of clock systems. Methods Enzymol. 2015, 552, 125-143.

22. Pathak, H.R.; Weissinger, F.; Terunuma, M.; Carlson, G.C.; Hsu, F.C.; Moss, S.J.; Coulter, D.A. Disrupted dentate granule cell chloride regulation enhances synaptic excitability during development of temporal lobe epilepsy. J. Neurosci. 2007, 27, 14012-14022. [CrossRef]

23. Hung, T.Y.; Chu, F.L.; Wu, D.C.; Wu, S.N.; Huang, C.W. The protective role of peroxisome proliferator-activated receptor-gamma in seizure and neuronal excitotoxicity. Mol. Neurobiol. 2019, 56, 5497-5506. [CrossRef]

24. Lai, M.C.; Wu, S.N.; Huang, C.W. The specific effects of OD-1, a peptide activator, on voltage-gated sodium current and seizure susceptibility. Int. J. Mol. Sci. 2020, 21, 8254. [CrossRef]

25. Racine, R.; Okujava, V.; Chipashvili, S. Modification of seizure activity by electrical stimulation. 3. Mechanisms. Electroencephalogr. Clin. Neurophysiol. 1972, 32, 295-299. [CrossRef] 
26. Maroso, M.; Balosso, S.; Ravizza, T.; Liu, J.; Aronica, E.; Iyer, A.M.; Rossetti, C.; Molteni, M.; Casalgrandi, M.; Manfredi, A.A.; et al. Toll-like receptor 4 and high-mobility group box-1 are involved in ictogenesis and can be targeted to reduce seizures. Nat. Med. 2010, 16, 413-419. [CrossRef]

27. Chang, Y.C.; Huang, A.M.; Kuo, Y.M.; Wang, S.T.; Chang, Y.Y.; Huang, C.C. Febrile seizures impair memory and cAMP response-element binding protein activation. Ann. Neurol. 2003, 54, 706-718. [CrossRef]

28. Pitkänen, A.; Schwartzkroin, P.A.; Moshe, S.L. Models of Seizures and Epilepsy; Elsevier Academic Press: Burlington, MA, USA, 2006.

29. Huang, C.W.; Cheng, J.T.; Tsai, J.J.; Wu, S.N.; Huang, C.C. Diabetic hyperglycemia aggravates seizures and status epilepticusinduced hippocampal damage. Neurotox. Res. 2009, 15, 71-81. [CrossRef]

30. Holmes, G.L.; Ben-Ari, Y. Seizures in the developing brain: Perhaps not so benign after all. Neuron 1998, 21, 1231-1234. [CrossRef]

31. Curia, G.; Longo, D.; Biagini, G.; Jones, R.S.; Avoli, M. The pilocarpine model of temporal lobe epilepsy. J. Neurosci. Methods 2008, 172, 143-157. [CrossRef] [PubMed]

32. Gillham, R.A.; Blacklaw, J.; McKee, P.J.; Brodie, M.J. Effect of vigabatrin on sedation and cognitive function in patients with refractory epilepsy. J. Neurol. Neurosurg. Psychiatry 1993, 56, 1271-1275. [CrossRef] [PubMed]

33. Dodrill, C.B.; Arnett, J.L.; Sommerville, K.W.; Sussman, N.M. Effects of differing dosages of vigabatrin (Sabril) on cognitive abilities and quality of life in epilepsy. Epilepsia 1995, 36, 164-173. [CrossRef] [PubMed]

34. Kälviäinen, R.; Aikiä, M.; Saukkonen, A.M.; Mervaala, E.; Riekkinen, P.J., Sr. Vigabatrin vs. carbamazepine monotherapy in patients with newly diagnosed epilepsy. A randomized, controlled study. Arch. Neurol. 1995, 52, 989-996. [CrossRef] [PubMed]

35. Mederos, S.; Sánchez-Puelles, C.; Esparza, J.; Valero, M.; Ponomarenko, A.; Perea, G. GABAergic signaling to astrocytes in the prefrontal cortex sustains goal-directed behaviors. Nat. Neurosci. 2021, 24, 82-92. [CrossRef] [PubMed]

36. Vossel, K.A.; Tartaglia, M.C.; Nygaard, H.B.; Zeman, A.Z.; Miller, B.L. Epileptic activity in Alzheimer's disease: Causes and clinical relevance. Lancet Neurol. 2017, 16, 311-322. [CrossRef]

37. Pitkänen, A.; Nissinen, J.; Jolkkonen, E.; Tuunanen, J.; Halonen, T. Effects of vigabatrin treatment on status epilepticus-induced neuronal damage and mossy fiber sprouting in the rat hippocampus. Epilepsy Res. 1999, 33, 67-85. [CrossRef]

38. Shin, C.; Rigsbee, L.C.; McNamara, J.O. Anti-seizure and anti-epileptogenic effect of gamma-vinyl gamma-aminobutyric acid in amygdaloid kindling. Brain Res. 1986, 398, 370-374. [CrossRef]

39. Myers, C.E.; Bermudez-Hernandez, K.; Scharfman, H.E. The influence of ectopic migration of granule cells into the hilus on dentate gyrus-CA3 function. PLoS ONE 2013, 8, e68208.

40. Jessberger, S.; Nakashima, K.; Clemenson, G.D., Jr.; Mejia, E.; Mathews, E.; Ure, K.; Ogawa, S.; Sinton, C.M.; Gage, F.H.; Hsieh, J. Epigenetic modulation of seizure-induced neurogenesis and cognitive decline. J. Neurosci. 2007, 27, 5967-5975. [CrossRef]

41. Zhu, K.; Yuan, B.; Hu, M.; Li, C.-J.; Xu, J.-H.; Feng, G.-F.; Liu, Y.; Liu, J.-X. Ablation of aberrant neurogenesis fails to attenuate cognitive deficit of chronically epileptic mice. Epilepsy Res. 2018, 142, 1-8. [CrossRef]

42. Pascente, R.; Frigerio, F.; Rizzi, M.; Porcu, L.; Boido, M.; Davids, J.; Zaben, M.; Tolomeo, D.; Filibian, M.; Gray, W.; et al. Cognitive deficits and brain myo-Inositol are early biomarkers of epileptogenesis in a rat model of epilepsy. Neurobiol. Dis. 2016, 93, 146-155. [CrossRef]

43. Sousa, K.; Decker, N.; Pires, T.R.; Papke, D.K.M.; Coelho, V.R.; Pflüger, P.; Pereira, P.; Picada, J.N. Neurobehavioral effects of vigabatrin and its ability to induce DNA damage in brain cells after acute treatment in rats. Psychopharmacology 2017, 234, 129-136. [CrossRef]

44. Best, J.L.; Acheson, J.F. The natural history of Vigabatrin associated visual field defects in patients electing to continue their medication. Eye 2005, 19, 41-44. [CrossRef]

45. Newman, W.D.; Tocher, K.; Acheson, J.F. Vigabatrin associated visual field loss: A clinical audit to study prevalence, drug history and effects of drug withdrawal. Eye 2002, 16, 567-571. [CrossRef]

46. Braun, K.P. Preventing cognitive impairment in children with epilepsy. Curr. Opin. Neurol. 2017, 30, 140-147. [CrossRef] [PubMed]

47. Nickels, K.C.; Zaccariello, M.J.; Hamiwka, L.D.; Wirrell, E.C. Cognitive and neurodevelopmental comorbidities in paediatric epilepsy. Nat. Rev. Neurol. 2016, 12, 465-476. [CrossRef] [PubMed]

48. Russo, E.; Citraro, R.; Scicchitano, F.; De Fazio, S.; Perrota, I.; Di Paola, E.D.; Constanti, A.; De Sarro, G. Effects of early long-term treatment with antiepileptic drugs on development of seizures and depressive-like behavior in a rat genetic absence epilepsy model. Epilepsia 2011, 52, 1341-1350. [CrossRef] [PubMed]

49. Tosun, D.; Siddarth, P.; Toga, A.W.; Hermann, B.; Caplan, R. Effects of childhood absence epilepsy on associations between regional cortical morphometry and aging and cognitive abilities. Hum. Brain Mapp. 2011, 32, 580-591. [CrossRef] 